\title{
Effects of Chlorella Alkali Extract on Blood Pressure in SHR
}

\author{
Kozo Okamoto, Yoshitomi Irzuka, * Tetsuo Murakami, * \\ Hideo Miyake, and Tsuneyuki Suzuki
}

We studied dietary effects on blood pressure and the incidence of stroke in SHRSP, and reported that a diet containing white fish meal, casein, euphausia etc, as a protein source could markedly depress the elevation of blood pressure, prevent the incidence of stroke and elongate the life span of SHRSP.

We artificially digested these protein sources to clarify their effective substances (Presentation at this Meeting). We discovered that chlorella was effective in preventing incidence of stroke but that it was difficult to study it in the same way as other protein sources. Therefore, we tried to search for its effective substances by different methods.

\section{Materials and Methods:}

1. Removal of pigments in chlorella

Chlorella contains several kinds of pigments (chlorophyll etc). As these pigments easily move into water or alcoholic layers and disturb the experiment, they were removed in advance by repeated treatment with methyl alcohol at room temperature until the extractive solvent was decolored.

2. Alkali treatment of chlorella

Twenty $\mathrm{Gm}$ of decolored chlorella was suspended in $2 \mathrm{~L}$ of distilled water. The $\mathrm{pH}$ was adjusted to 9.3 . The solution was stirred slowly at $60^{\circ} \mathrm{C}$ for 15 hours and then centrifuged at $4,000 \mathrm{rpm}$ for $5 \mathrm{~min}$. Supernatants were condensed to about $30 \mathrm{ml}$ by a rotary evapolator, cold ethyl alcohol was added to make the ethyl alcohol content $70 \%$, and the results werc kept in cold water for 3 hours. After centrifugation $(15,000 \mathrm{rpm}$ for $20 \mathrm{~min}$ ), the alcohol soluble portion (alkali extract) was condensed to $30 \mathrm{ml}$.

3. Separation of chlorella alkali extract

The chlorella alkali extract was fractionated by gel filtration on Sephadex G25 fine (column : $2.5 \times 50 \mathrm{~cm}$ ), eluted with distilled water, collected $5 \mathrm{ml}$ in each tube, and with the absorption spectra at $280 \mathrm{~nm}$, separated into 4 fractions (A, B, C, and D).

4. Effects on blood pressure

The alkali extracts were administered to SHRSP and SHR (blood pressure 180 to $230 \mathrm{mmHg}$ ) either intravenously, intraperitoneally, or intragastrically; and injected into normotensive Wistar rats intravenously.

Blood pressure was measured chronologically without anesthesia by the tailpulse pickup method. Five to 16 animals were used in each group.

From the Department of Pathology, Kinki University School of Medicine and Research Institute of Food Science,* Kinki University, Osaka-fu. 
Results :

1. Since fraction A showed a depressive effect, it was fractionated by gel filtration on Sephadex G-75, and separated into 2 fractions $\left(A_{1}\right.$ and $A_{2}$ ). When these fractions were injected into SHRSP and SHR intravenously, the depressive effect of fraction $A_{1}$ was stronger than that of fraction $A_{2}$.

The following results for fraction $A_{1}$ were obtained.

1) Intravenous injection ( $3 \mathrm{mg} / 100 \mathrm{Gm}$ of body weight): Blood pressure in SHRSP and SHR fell after $30 \mathrm{~min}$ and showed a fall of $63 \pm 21(\mathrm{M} \pm \mathrm{SD}) \mathrm{mmHg}$ after $60 \mathrm{~min}$. The blood pressure in normotensive rats also showed a fall of $32 \pm$ $0.6 \mathrm{mmHg}$ after $60 \mathrm{~min}$.

2) Intraperitoneal administration (15 mg/rat): Blood pressure in SHRSP and SHR showed a fall of $47 \pm 27 \mathrm{mmHg}$ after 2 hours, and of $27 \mathrm{mmHg}$ after 3 hours.

3) Intragastric administration ( $30 \mathrm{mg} / \mathrm{rat}$ ): Blood pressure of SHRSP and SHR showed a fall of $20 \mathrm{mmHg}$ after 3 hours, and 16 or $11 \mathrm{mmHg}$ after 4 or 5 hours, respectively.

2. Fraction $A_{1}$ showed a minimum of $257 \mathrm{~nm}$ and a maximum of $278 \mathrm{~nm}$ in UV absorption spectra, and qualitatively was positive in ninhydrin reaction and in the phenol-sulphuric acid method.

Summary:

When chlorella was treated with alkali after decolorization by methyl alcohol and then fractionated by gel filtration, the fraction showed a depressive effect. The blood pressure of SHRSP and SHR showed a fall of an average of $63 \mathrm{mmHg} 1$ hour after intravenous administration, $47 \mathrm{mmHg} 2$ hours after intraperitoneal administration. The blood pressure of normotensive Wistar rats also showed a fall of an average of $32 \mathrm{mmHg} 1$ hour after intravenous administration.

This study was supported by the Science and Technology Agency of Japanese Government, the Ministry of Education, the Japanese Society for the Promotion of Science, and the National Heart and Lung Institute of NIH (USA) (HL 17754-03). 